\title{
Specific Risks associated with the Manufacture of Airplanes
}

\author{
Niels Bumann
}

Faculty of Engineering, University of Porto, PT (up201803664@fe.up.pt) ORCID: 0000-0002-5665-6063 https://doi.org/10.24840/978-972-752-260-6_0068-0072

\begin{abstract}
Introduction: The aviation industry is growing fast, Boeing and Airbus are the biggest manufacturers in this area. The production and manufacture in the Aviation sector contain specific risks and hazards especially according to the size of the different parts of the airplane. This paper reviews and summarizes some special risks about this production chain, based on the manufacture line of an airbus aircraft. Methodology: The methodology used for this paper is a literature research. Different journal databases and library catalogues have been searched. Qualitative and quantitative studies have been included. Results and Discussion: Production of aircrafts dangles multiple dangers. The specific risks are mostly according to the size of the parts of the airplane, also the scale and level of the different operations are very complex. One big risk factor in the production of an Airbus airplane, is transportation. Airbus produces its parts all over Europe. The transportation to different locations is complicated and executed by different vehicles, ranged from special trucks to Beluga airplanes. To be highlighted here are the wings, which are produced in the United Kingdom and have to been maneuvered through small towns and streets, which are not designed to carry these big transports. This action contains multiple dangers, for the traffic, for the infrastructure and for the people involved in this process. Another specific risk, associated with the manufacture of an airplane is the size of the whole production area. In the size of small towns with big buildings to store and contain all parts of the airplanes, risks and dangers can fast be overlooked. Due to the size of the parts, many operations must be performed at great height. Operators face the risks of falling down the structure or dropping tools onto other people. The fact, that even a small risk that has not been adequately addressed poses a danger to hundreds of people who could later crash in this aircraft, highlights the aircraft industry of others. Conclusions Problems in this area are known, lots of different approaches were made in the past to identify all the risks and dangers, from the detailed approach of checking and analysing every single part, to the approach of including the bigger picture, containing risk scores based on ubiquity and geopolitical risks as well as ERP approaches in the whole manufacturing process.
\end{abstract}

Keywords: Aviation, Manufacture, Transportation, Aircraft, Airplane.

\section{INTRODUCTION}

The Aviation sector is growing rapidly. Aircraft production has increased significantly in recent years and decades. Airbus alone has recorded a 28 percent increase in deliveries over the past five years. This means a number of approximately 800 deliveries in 2018, as shown in Figure 1. These statistics also mean that production has increased in recent years (Airbus). The question of risks and dangers arises. The manufacture of airplanes is a special production sector with various risks. The workers and people that are involved in the production process are exposed to dangers, which occur not exclusively, but specifically here. Next to the risks that the people are exposed to, also the infrastructure and other aspects are exposed to dangers in the process of manufacturing an aircraft.

\section{METHODOLOGY}

The method used in this paper is a literature research. Various online library catalogues, such as the library of the Technical University of Darmstadt, Germany and the online library of the Faculty of Engineering of University of Porto have been searched for references and studies about this topic. Also, different journal databases with multiple different keywords, such as risk assessment, safety, transportation, aviation, aircraft, production and manufacture have been searched. Examples here are the websites of Scopus, Science Direct, Web of Knowledge, Google Scholar and Springer. For this research, the search ranged from articles to journals, books and conference papers. It was searched mostly for papers, published in the last four years (since 2015). If articles were found, which are important for the topic, these were also considered, even if they are older than four years. The languages searched in, were English and German. For the statistics from companies, such as Airbus, the data was taken directly from 
their homepage.

AIRBUS

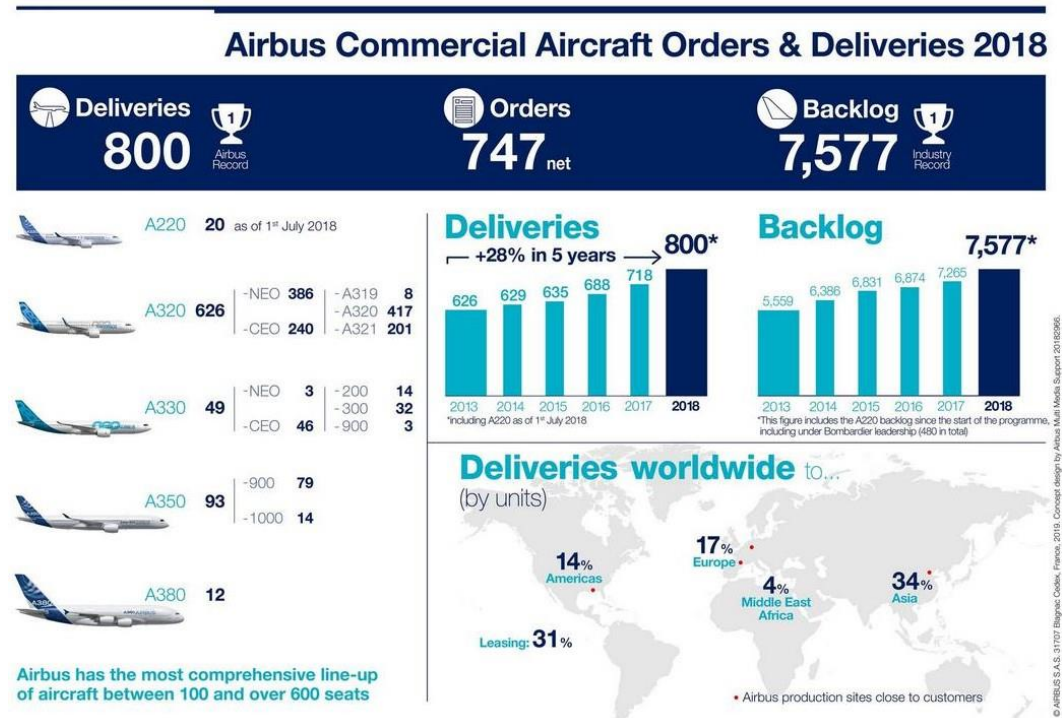

Figure 1. Airbus deliveries in the past five years (Airbus.com)

\section{RESULTS AND DISCUSSION}

The production of an airplane dangles multiple dangers. It is important that every step is very well coordinated and planned. The production of an Airbus A320 takes about one year, over this cycle time, lots of risks and dangers occur (Airbus Press Office, 2019). If the risks are not treated correctly, the consequences are dangerous, not only for the workers and people that are involved in the production process, but also for the passengers that will fly with the airplane later on. Mechanical failures made whilst constructing and producing airplane parts lead to multiple crashes in the past. Examples here are the crash of a DC-10 at Chicago in 1979 happened due to engine failure, another DC-10 crashed in Paris in 1979 due to problems with the door system. Lots of people died because risks in the production process were overseen (Janic, 2000). Next to these later occurring risks, the workers in the manufacturing process face lots of dangers. One of these risks is the scale of the product. The size of the final product, an aircraft, means that the individual components that make up the product are also larger compared to other products (Bates, Sturges \& Hutchinson, 1999). This implies, that workers have to work at greater heights to carry out their tasks. Many structures must be used to provide a safe and firm hold, both for the components and for the workers. Still, operatives are facing the danger of falling down or dropping tools on other people while working on these structures (Figure 2). A further factor in this area is that due to the shape of the aircraft much overhead work has to be carried out, sometimes at great heights. This work has been proven to be the most stressful for the human body, and these risks can lead to many physical problems with the body. One big risk factor in the aviation industry is the transportation of the parts. Most airplanes are produced at different locations. At the example of Airbus, they produce in various countries in Europe (Figure 3). Especially the transportation of the wings are often risky and dangerous due to the location of the factory in the United Kingdom (UK) (Mas Morate et al., 2013). The wings have to be maneuvered through small towns and roads, which are not constructed for carrying such a big transport, as seen in Figure 4. 


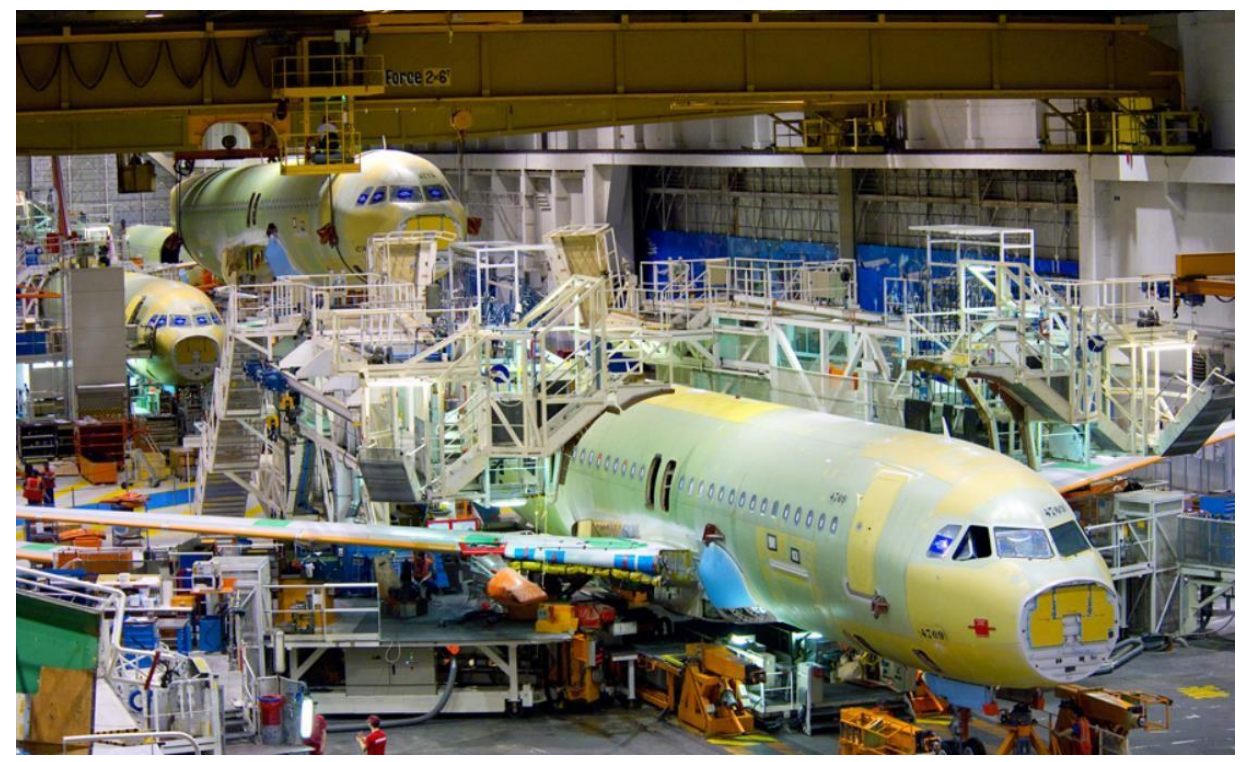

Figure 2. Airbus Plant (Assembly Magazine)

Hazards occur for the traffic, the infrastructure, the workers and external people. Also, the traffic has to be prevented and shut down at some points because operating with the wings cannot continue without risks. Besides these problems, the transport of parts of the aircraft is carried out by Beluga airplanes, container ships and Roll-on/Roll-off vessels (Fig. 3). In addition to transport between the individual factories, there are also risks associated with transport within a site. Some of the parts are so large that big transport vehicles are needed, which are moved either by articulated lorry or by hand with remote control. Here, too, accidents can occur, some of which are particularly dangerous for the workers due to the size of the transports. Next to these risks, mostly according to the scale and complexity of the aircraft manufacture, lots of dangers occur, that are also known in other production lines. Starting with errors that occur during production planning. Processes that are dangerous from the outset due to organizational errors. These errors can appear in a wide range. Starting with the wrong composition of components, through the use of the wrong machines, to electrical faults that can lead to fires or short circuits, which in turn can be dangerous for the workers. The shaping of the material is dangerous, due to the high temperature, workers have to deal with. The assembly of the individual parts is dangerous as high forces are used, especially screws are exposed to high residual stresses. Many machines are used to support the workmen, they can fail or malfunction, which can be dangerous for the workers. The spraying of the parts at the end is poisonous, the operatives have to be careful that they wear the right protective clothing to avoid damage. Besides all these technical and mechanical risks and dangers, there is still the danger of human failure. This can be the result of many causes, for example, insufficient concentration, inability or fatigue due to shift work. However, these risks are difficult to assess as they depend on the human factor and are therefore different for each worker. The risks mentioned are only a few in the entire production process. Many other risks are not known or are classified as harmless. 
A320 Family workshare + transport

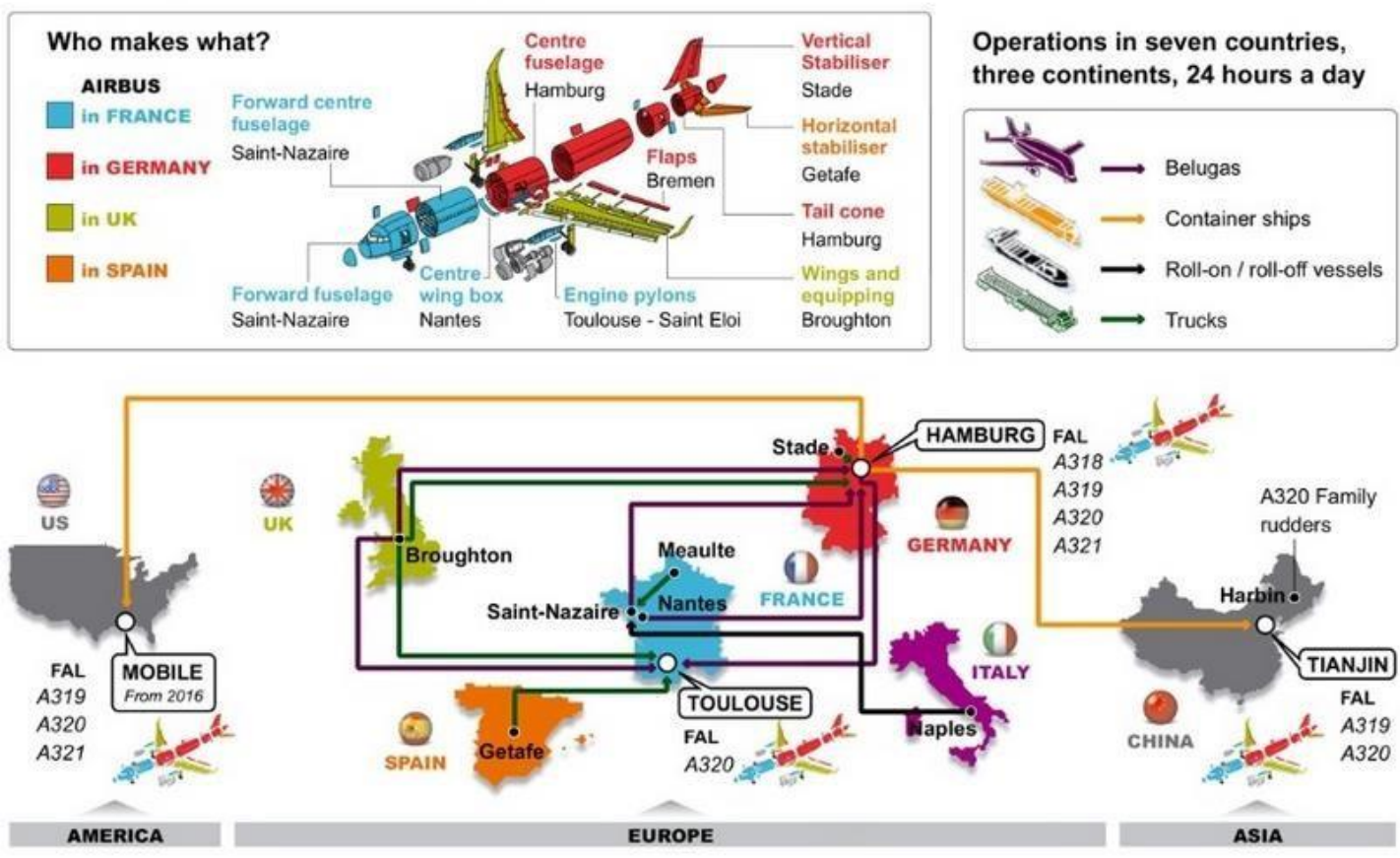

Figure 3. Production sites and transport vehicles of an A320 from Airbus (Modern Airlines)

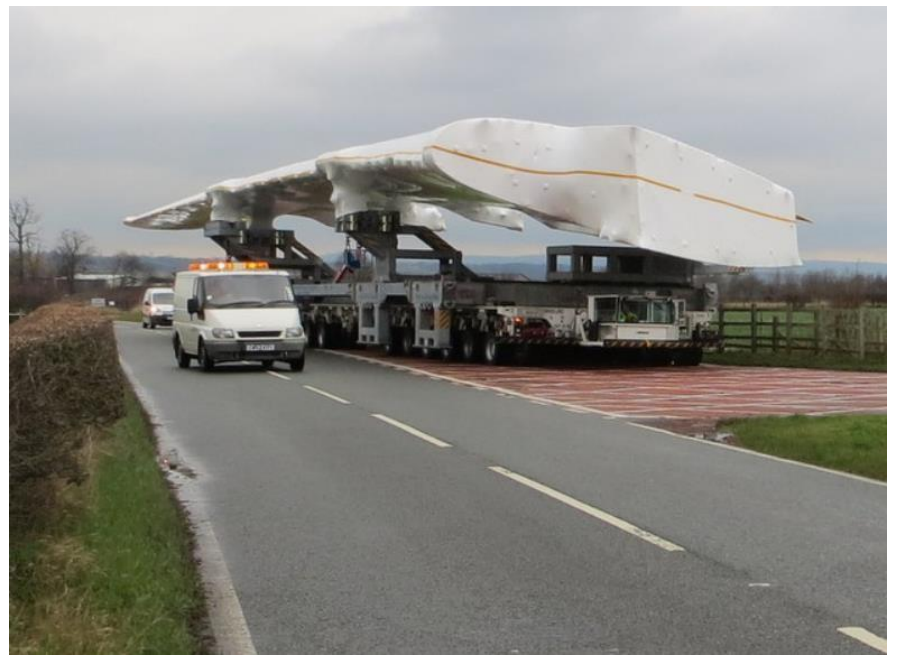

Figure 4. Transport of an Airbus wing in the United Kingdom (Geograph.org)

\section{CONCLUSIONS}

There are many different risks involved in producing aircraft, many of which are known. However, there are always risks and dangers that are overlooked or classified as harmless. There are lots of different approaches to finding and classifying these risks. These approaches range from the classification of every single part of an aircraft, starting with the smallest screw, to assessment procedures involving component ubiquity and geopolitical instabilities (Bains et al., 2016). Other approaches also include enterprise resource planning. These methods help to identify and classify the risks and dangers in production, but risks remain, such as the transport 
of parts (Sharma \& Gupta, 2014). Hazards must continue to be expected here. It will never be possible to eliminate all risks during production. In order to find the best method to improve risk assessment, the safety studies must be intensified, new approaches must be developed, and the risk assessment process must be improved. This paper gives a first short overview of the difficulties in the manufacturing process of an aircraft. More studies need to be carried out to get a complete overview and proceed further.

\section{References}

Mas Morate, F., Menéndez Cuñado, J. L., Oliva Olvera, M., \& Ríos Chueco, J. (2013). Collaborative Engineering: an Airbus case study. Procedia Engineering, 63(null), 336-345.

Sharma, A., \& Gupta, S. (2014, February). Identifying the role of ERP in enhancing operational efficiency and supply chain mobility in aircraft manufacturing industry. In 2014 International Conference on Issues and Challenges in Intelligent Computing Techniques (ICICT) (pp. 330-333). IEEE.

Bains, P., Ferris, K., Gregoire, J., Kim, J., Kozloski, J., Lazenby, J., ... \& Fleming, C. (2016, April). Risk analysis of globalized airline supply chains. In 2016 IEEE Systems and Information Engineering Design Symposium (SIEDS) (pp. 44-48). IEEE.

Airbus Press Office (2019). A320 FAMILY: The most successful aircraft family.

Bates, M. B., Sturges, J. L., \& Hutchinson, B. (1999). Project Management Techniques and Procedures: A comparison of construction contracting and aircraft manufacture. In Proceedings of the 2nd International Conference on Construction Industry Development, and 1st Conference of CIB TG (Vol. 29).

Plan, A. C. E. (2007). Federal Aviation Administration. US Department of Transportation, Washington, DC, (May, 1983).

Janic, M. (2000). An assessment of risk and safety in civil aviation. Journal of Air Transport Management, 6(1), 43-50.

Altfeld, H. H. (2016). Commercial aircraft projects: Managing the development of highly complex products. Routledge.

Turner, J. S. (n.d.). Moving an Airbus A380 wing \#2 (C) John S Turner. Retrieved April 2, 2019, from https://www.geograph.org.uk/photo/3829924

Doornbos, P. (2015). Airbus A320 - Assembly. Retrieved April 6, 2019, from http://www.modernairliners.com/airbusa320-introduction/airbus-a320-assembly/

Airbus achieves new commercial aircraft delivery record in 2018. (n.d.). Retrieved April 7, 2019, from https://www.airbus.com/newsroom/press-releases/en/2019/01/airbus-achieves-new-commercial- aircraft-deliveryrecord-in-2018.html

Airbus Begins Construction of $\$ 300$ Million Assembly Plant in Alabama. (2019, February 12). Retrieved April 7, 2019, from https://www.assemblymag.com/articles/94754-airbus-begins-construction-of-300-million- assembly-plant-inalabama 